\begin{tabular}{l|l} 
Variants & $\begin{array}{l}\text { Variants } \\
\text { The Journal of the European Society for Textual } \\
\text { Scholarship }\end{array}$
\end{tabular}

$12-13$ | 2016

Varia

\title{
Genetic Criticism with Textual Criticism: From Variant to Variation
}

\section{Daniel Ferrer}

\section{OpenEdition \\ Journals}

\section{Electronic version}

URL: http://journals.openedition.org/variants/284

DOI: $10.4000 /$ variants.284

ISSN: 1879-6095

\section{Publisher}

European Society for Textual Scholarship

\section{Printed version}

Date of publication: 31 December 2016

Number of pages: $57-64$

ISSN: 1573-3084

\section{Electronic reference}

Daniel Ferrer, «Genetic Criticism with Textual Criticism: From Variant to Variation », Variants [Online], 12-13 | 2016, Online since 01 May 2017, connection on 05 May 2019. URL : http:// journals.openedition.org/variants/284 ; DOI : 10.4000/variants.284 


\section{Genetic Criticism with Textual Criticism: From Variant to Variation}

Daniel Ferrer

Abstract: It has been necessary to make a clear distinction between genetic criticism and textual criticism. I suggested that textual criticism is a science of repetition and genetic criticism a science of invention; that the aim of textual criticism is to establish the text (by eliminating its variants), whereas genetic criticism destabilizes the text by confronting it with its actual or potential versions. It now seems required to qualify this general opposition: because it is sometimes impossible to distinguish between creative variants and variants of transmission and also because it is not an adequate description of some of the more interesting work being done in the field of textual criticism. Some of the models that textual critics have put forward can be a source of inspiration for geneticists. Understanding variants as a form of variation can be a more useful way of approaching the question. Keywords: genetic criticism, textual criticism, revision, variant, composition history, transmission history, James Joyce.

RolAnd BARTHES used to say that it was unfair that typists should not have the right to an unconscious: nobody cares about their parapraxes except to eliminate them $(1975,100)$. Most traditional textual critics would agree with this commonsensical approach to error: their goal has been to recover the authentic text from the distortions that corrupted it in transmission. From this point of view variant readings are annoying parasites that should be eliminated on the way towards the prelapsarian singularity of the text.

Yet if variants are theoretically despised, practically they are treasured, collated with the greatest care and subjected to a very sophisticated treatment. It is not as marks of authorial hesitancy but specifically as scribal departures that variants became an object of study. ${ }^{1}$ Errors have been classified with great subtlety, on the principle that you must understand your enemy to defeat him. It is obvious that traditional philology is absolutely fascinated by them

1 In some cases, we cannot be quite sure that some of the variants in the tradition are not scribal, but authorial. Giorgio Pasquali (1952) has suggested that it is probably the case in the works of Ovid, for instance. 
(a kind of Stockholm syndrome). We could say that the unconscious of the typist has in fact become an object of study: perhaps not the personal unconscious that Barthes had in mind, but at least the linguistic and historical systems responsible for the copyist's mistakes.

After some time, textual criticism realized that the appropriation of the text could also be interesting in itself, and perhaps as interesting as the retrieval of the original text. Textual scholars began to study variants not as mere deformations of an original but as the interaction of two systems, interfering with one another, as a super system or diasystem combining the two, or even - I am referring specifically to Cesare Segre's theory $(1976 ; 1979)$ - as a kind of creolization of the original system, i.e. the appropriation of the materials of a basic language in order to produce an autonomous language, ruled by its own grammar. ${ }^{2}$

When textual criticism reaches this point, the opposition between textual criticism and genetic criticism fades away and tends to disappear: I have written elsewhere that textual criticism is a science of repetition and genetic criticism a science of invention; that the aim of textual criticism is to establish the text (by eliminating its variants), whereas genetic criticism destabilizes the text by confronting it with its actual or potential versions (Ferrer 2002). ${ }^{3}$ This rough opposition needs to be considerably qualified, however.

When textual criticism adopts such a point of view - treating variants as parts of an autonomous system that interferes with, and remodels, the original system - it can become a source of inspiration for genetic criticism. A similar kind of interference between systems occurs in the course of writing: the point of view of the writer constantly changes during the creative process, so that what is already written must be reinterpreted from a - marginally, in most cases, but sometimes radically, new - perspective, somehow like Segre's medieval scribe striving to assimilate the text he

2 The concept of de-creolization may help describe the effects of editorial emendations. Since creole languages rarely attain official status, the speakers often feel compelled to conform their speech to the parent language (which is usually a politically or culturally dominant language). Such de-creolization typically brings about a post-creole speech characterized by a mixture of fossil remains and hypercorrections.

3 For a more recent formulation of this position, see Ferrer 2011. 
is copying into his own linguistic system. Variants are traces of this process of reinterpretation that sometimes amounts to a creolization: if the writer's point of view did not change, there would be no modifications, no cancellations, no additions...

There is however, something that is lacking for this model to be entirely adequate for the needs of genetic criticism. I would like to suggest that we could supplement it by making use of the notion of variation.

The words "variant" and "variation" both designate elements that are at the same time similar and different, and they are often loosely - used interchangeably. Generally, we speak of "variants" when there is a choice between elements regarded as equivalent, and of "variation" when similar elements are juxtaposed in space or in time (see Ferrer 2009). The prime example is of course musical variation, like the Goldberg or the Diabelli variations, but we can also speak of pictorial variations and textual variations.

The problem is that even musicologists find it difficult to define exactly what counts as a variation. It is something that is both similar and different, but we could say that about practically any two entities, so any piece could be a variation on another.

Roman Jakobson's two linguistic axes are helpful here. Variants are to be found on the paradigmatic axis, the axis of selection between elements that are considered equivalent, whereas variations occur along the syntagmatic axis, the axis of combination, but they still have to do with equivalence. Variants represent a special manifestation of the poetic function as Jakobson famously describes it: "the projection of the principle of equivalence from the axis of selection on to the axis of combination" $(1960,358)$.

Jakobson's analysis is particularly interesting because it shows that the poetic takes the form of a fundamentally genetic mechanism (the choice between different possibilities and the actualization of the virtual), but it does not really help us that much with our definition of variation, since he does not define what equivalence is. We can only infer that variation is not identity; otherwise, there would be no selection, no options to choose from.

The American philosopher Nelson Goodman offers the best explanation: a passage functions as a variation of another passage only when it refers to it in a certain way $(1988,68)$, by exemplifying some of its properties. Goodman's favourite example is the 
tailor's swatch of cloth: it has many properties — shape, weight, being made on a certain day of the week, for instance; but these are considered irrelevant because the swatch is only meant to exemplify its colour and its weave.

Goodman also emphasizes that differences have a referential value as well as similarities. Differences can exemplify contrastively some features of the theme. How can a variation exemplify a feature it does not have? Or how can it refer to the theme by exemplifying features that the theme does not have? How can an absent feature exemplify something? These are very important questions in our field. In the same way, Goodman says, as we refer ironically to a giant by calling him Tiny, or as we refer to the rain outside by calling it "our beautiful Parisian weather".

Let us try to illustrate this. Take two sentences from the "Aeolus" chapter of James Joyce's Ulysses: "Grossbooted draymen rolled barrels dullthudding out of Prince's stores and bumped them up on the brewery float. On the brewery float bumped dullthudding barrels rolled by grossbooted draymen out of Prince's stores" (Joyce 1986, 96; 7. 21-24). These sentences can be likened to musical variations: the second sentence appears as a variation on the first one; it alludes to it by exemplifying some of its features. To be more specific, there is both a direct allusion, since the same words are repeated, and a contrastive allusion to the order of the words, since this order is conspicuously inverted.

An examination of the genesis of this passage yields significant variants, both scribal and authorial. On the fair copy (the Rosenbach manuscript), we can see that Joyce wrote only the first of the two sentences which was then positioned at the opening of the chapter (Joyce 1975, 1: 112-13); the sentence made its way unchanged into the typescript that was sent to the Little Review for serialization.

But here is the text as it appeared in the October 1918 issue of the magazine: "Grossbooted draymen rolled barrels dullthudding out of Prince's stores and bumped them up on the brewery float. Grossbooted draymen rolled barrels dullthudding out of Prince's stores and bumped them up on the brewery float" (Joyce 1918, 26). The sentence was repeated, probably by mistake (Groden 1977, 70n). It is difficult to probe the unconscious of the printers here. Hans Walter Gabler suggests that the mistake may have been due to the printer's accidental omission of the initial dropped capital 
and of the capitalized first word, oversights that prompted the compositor to reset the whole sentence, forgetting, in the process, to delete the earlier attempt. ${ }^{4}$ It is also possible that the typesetter was unconsciously affected by the text - assuming that he read his copy before setting it - because this is what appears on the next page: "The machines clanked in threefour time. Thump, thump, thump. Now if he got paralysed there and no one knew how to stop them they'd clank on and on the same, print it over and over and up and back. Monkeydoodle the whole thing. Want a cool head" (Joyce 1986, 74; U 7.101). This is exactly what has happened at The Little Review: the printing machine got out of hand and monkeydoodled the whole thing.

Be that as it may, this scribal, or rather mechanical, variant triggered an authorial variant. During correction, Joyce decided to keep the repetition of the words, but he introduced a variation on the word order in the repeated sentence. Since the chapter is devoted to rhetoric and is saturated with rhetorical figures, it afforded an occasion to further exhaust the paradigm by introducing one more figure (a chiasmus); with a single stroke it performed a double projection of the paradigm on the syntagm.

The great Joyce critic Hugh Kenner argued that the original single sentence "already seems to foresee the sentence he was later to insert after it" $(1987,63)$. I find this remark interesting and amusing, because the chapter (though not this particular sentence) actually predicted that the mechanics of printing would get out of hand and result in repetition. More importantly, Kenner's remark is symptomatic of a very natural attitude that we have towards texts, particularly those texts that we consider masterpieces: we cannot accept that they have not, somehow, always been such as they are, and we feel that the labour of genesis only consists in revealing what was present as a germ that only needed to be developed. The repetition of "already" and the form "he was to" suggest a predestination of the text.

But the qualification ("seems to foresee") shows that Kenner is not entirely the victim of this retrospective illusion. Retrospection is not only a naïve illusion; it is a fundamental genetic mechanism

4 Private communication, 2013. 
— and using the model of the variation is an attempt to understand this mechanism.

Goodman insists that variations interpret the theme. We can say likewise that genetic variants interpret earlier versions. Variation exemplifies, directly or contrastively, qualities that were latent in the original form. This is what Kenner means when he says that the first sentence foresees the second (more accurately, it foresees the double sentence that constitutes the future variant). But this is a prediction a posteriori, what has been called, in another context, "backshadowing", "a kind of retroactive foreshadowing" (Bernstein 1994, 16). The quaint choice of words of the early sentence, its alliterative rhythm and its tendency to fold upon itself are much more in evidence when seen in conjunction with the second. But we can say as well that the second sentence "remembers" the first one. It only exists in memory of the first (to use an ambiguous phrase well exploited by Jacques Derrida [2013]).

Of course, this is an easy thing to say here, where the variant consists of an addition, and where the variation occurs in presentia. But I would like to suggest that it is also true in cases of substitution, or even deletion, where the variation occurs in absentia.

Let us take the same example at a further stage of development. The passage was completely overhauled on page proofs. Joyce inserted new paragraphs at the beginning, so that the two sentences no longer opened the chapter. More importantly, he inserted, in accordance with the new aesthetics that he had developed while writing the subsequent chapters, newspaper headlines that completely changed the character of the episode.

In this context, it appears that the single sentence is not only a superseded variant of the double one. As a former incipit of the chapter, it is also a variant of the opening of the chapter in the final version of the text: a newspaper heading, right in the middle of a novel. A slightly quaint opening sentence has been replaced by a stunningly revolutionary beginning (for the time).

But this hyper-modernist beginning of the chapter in the book version "remembers" the more subdued stylistic audacity of the incipit as it was published in the Little Review. ${ }^{5}$ It alludes to it by exemplifying, directly and contrastively, some of its properties.

5 For the notion of "memory" of the genetic context, see Ferrer 1996 and 2011. 
Admittedly, for the ordinary reader who is not "genetically informed" (aware of the avant-texte), it is an imperceptible allusion; but this allusion is nevertheless present in the text as an active force. The idea that an allusion could be imperceptible may seem paradoxical; still, it is a common feature of Joyce's works. Finnegans Wake is saturated with such allusions. Joyce's readers know that they are there, that they play an important part in the book, and thus that it is worth chasing them up with reference books and glossaries. But no reader will be able to recognize all of them, for this would require the impossible: speaking dozens of languages and knowing by heart thousands of books and recondite sources.

From the point of view of the author, in the course of writing, variations occur in presentia. When making a change and producing a variant, a writer is (usually) well aware of the version that it supersedes: the new variant is a deliberate exemplification, direct or contrastive, of the relevant properties in the discarded version. From the point of view of the critic, reading the variant as a variation clarifies the dynamic interaction of the versions that takes place during the creative process.

It is to be hoped that many readers will become genetically informed and transform variants (authorial variants and sometimes also variants of transmission, as we have seen that the two can be inextricably linked), into powerful means of interpreting the text, by treating them as variations.

\section{Bibliography}

Barthes, Roland. 1975. Roland Barthes par Roland Barthes. Paris: Seuil. Bernstein, Michael André. 1994. Foregone Conclusions: Against Apocalyptic History. Berkeley: University of California Press.

Derrida, Jacques. 2013. "Two Words for Joyce". In Andrew J. Mitchell and Sam Slote (eds), Derrida and Joyce: Texts and Contexts. Albany: State University of New York Press.

Ferrer, Daniel. 1996. “Clementis's Cap: Retroaction and Persistence in the Genetic Process". Trans. Marlena G. Corcoran. In Michael Contat et al. (eds.), Drafts, special issue of Yale French Studies, 89, 223-36.

—_. 2002. "Production, Invention and Reproduction: Genetic Criticism vs. Textual Criticism". In Neil Fraistat and Elizabeth 
Bergmann Loizeaux (eds), Reimagining Textuality: Textual Studies in the Late Age of Print. Madison, Wisconsin: Wisconsin University Press, 48-59.

—. 2009. "Variant and Variation: Towards a Freudo-BathmologicoBakhtino-Goodmanian Genetic Model?" In J. E. Jones and W. Kinderman (eds), Genetic Criticism and the Creative Process: Essays from Music, Literature, and Theater. Rochester: University of Rochester Press, 35-50.

__. 2011. Logiques du brouillon: modèles pour une critique génétique. Paris: Seuil.

Goodman, Nelson. 1988. "Variations on Variation - or Picasso back to Bach". In Nelson Goodman and Catherine Elgin (eds), Reconceptions in Philosophy and Other Arts and Science. Indianapolis: Hackett, 66-82.

Groden, Michael. 1977. Ulysses in Progress. Princeton: Princeton University Press.

Jakobson, Roman. 1960. "Closing Statement: Linguistics and Poetics". In T. Sebeok (ed.), Style in language. New York: Wiley, 350-77.

Joyce, James. 1918. “Ulysses: Episode VII". The Little Review, October, $26-51$.

—_. 1975. Ulysses: A Facsimile of the Manuscript. Ed. Clive Driver. New York and Philadelphia: Octagon.

—_. 1986. Ulysses: The Corrected Text. Ed. Hans Walter Gabler et al. New York: Vintage Books.

Kenner, Hugh. 1987. Ulysses. Baltimore: The Johns Hopkins University Press.

Pasquali, Giorgio. 1952. Storia della tradizione e critica del testo. Florence: Le Monnier.

Segre, Cesare. 1976. "Critique textuelle, théorie des ensembles et diasystème". Bulletin de l'Académie Royale de Belgique, 62, pp. 276-92.

—_. 1979. "Les transcriptions en tant que diasystèmes". In J. Irigoin and G. P. Zarri (eds), La pratique des ordinateurs dans la critique des textes. Paris: Colloques internationaux du CNRS, pp. 45-49. 